\title{
Imagery perspective and source monitoring in imagination inflation
}

\author{
LISA K. LIBBY \\ Cornell University, Ithaca, New York
}

\begin{abstract}
The present experiments suggest that imagery perspective-first person (own) versus third person (observer's) -influences source-monitoring judgments. Imagination inflation (Garry, Manning, Loftus, \& Sherman, 1996) occurs when imaginary experience with events is mistaken for real experience. In Experiment 1, the perspective used to visualize real past events depended on memory test wording ("remember doing?" vs. "happened to you?"). Experiment 2 manipulated the perspective used to visually imagine counterfactual events and showed that the effect on imagination inflation depended on memory test wording. Imagination inflation was most likely when memory test wording encouraged participants to visualize real events from the same perspective as they had used to imagine counterfactual ones. Imagination inflation may result not simply from having created imaginary representations of events, but also from having created representations that match the decision criteria used in source monitoring.
\end{abstract}

\begin{abstract}
... the re-recollected past and the imaginary past may be much the same ... there is nothing unique in the object of memory ... the object of memory is only an object imagined in the past ... to which the emotion of belief adheres. (James, 1890/1950, p. 652)
\end{abstract}

Consistent with James's notion, the source-monitoring framework (Johnson, Hashtroudi, \& Lindsay, 1993) holds that representations of the past are not tagged with a label specifying whether they are memories of real or of imagined events. Rather, what James calls "the emotion of belief" is determined on line as a function of the interaction between two factors: the qualitative characteristics of the representation and the decision criteria applied to those characteristics. On average, memories of experienced events and of imagined events differ qualitatively. Memories of experienced events contain more perceptual detail and less evidence of the cognitive operations used to create them than do memories of imagined events (Johnson, Foley, Suengas, \& Raye, 1988).

People appear to use these average differences between memories of real and imagined events as one basis for source-monitoring decision criteria (e.g., Goff \& Roediger, 1998; Johnson, Raye, Foley, \& Foley, 1981). However, other research has shown that source-monitoring criteria are flexible and responsive to present circumstances. Thus, a factor as simple as a modification in memory test format

I thank Dick Neisser for numerous invaluable discussions that contributed to the inception and progress of this research. I also thank Brian Kim for assistance in data collection, as well as Richard Eibach, Mike Ross, Maryanne Garry, and two anonymous reviewers for helpful suggestions on earlier versions of this manuscript. Correspondence concerning this article should be addressed to L. K. Libby, Department of Psychology, University of Waterloo, 200 University Ave. W., Waterloo, ON, 2NL 3G1Canada (e-mail: 1libby@watarts.uwaterloo.ca). can cause people to change their source-monitoring criteria, focusing on different aspects of their representations of the past, and arriving at different judgments regarding the source of those representations (Dodson \& Johnson, 1993; Johnson et al., 1997; Lindsay \& Johnson, 1989; Marsh \& Hicks, 1998). Such findings make the point that beliefs about source are a function not just of the characteristics of event representations, but also of the fit between these characteristics and the criteria used to evaluate them on line.

Although much of the research in the source-monitoring tradition has involved memory for laboratory stimuli, the principles of the source-monitoring framework apply to autobiographical memory as well (e.g., Johnson et al., 1988). Source-monitoring judgments take on particular significance in this case, because they determine people's beliefs about the contents of their personal past. Garry and colleagues (Garry, Manning, Loftus, \& Sherman, 1996) have demonstrated that imagining counterfactual childhood events can lead people to become more certain that those events actually did occur in the past. Dubbed imagination inflation, this effect can be explained by errors in source monitoring: People mistake the product of their imagination for the product of real past experience. If source judgments depend on the relation between representation characteristics and decision criteria, imagination inflation should depend on these factors as well. In other words, imagination inflation should result not simply from having created imaginary representations of events, but also from having created representations that match the decision criteria used in source monitoring.

In the present experiments, this idea was investigated in the domain of visual imagery. Visual images can be constructed from two different perspectives (Libby \& Eibach, 2002; Nigro \& Neisser, 1983; Robinson \& Swanson, 
1993). When using a first-person perspective, one sees the event as if looking through one's own eyes; when using a third-person perspective, one sees the event as if from an outside observer's perspective, so that the self is in the image. Because memory is reconstructive, the imagery perspective that people use to recall real past events is malleable and influenced by present circumstances (Libby, 2003; Libby \& Eibach, 2002; Nigro \& Neisser, 1983). For example, Nigro and Neisser (1983, Study 4) told participants either to focus on the objective circumstances of a past event or to focus on their original experience of it. The former instructions suggest a removed standpoint on the past, and the latter suggest an involved standpoint. The memory perspective that the participants used in each condition reflected these suggestions. The participants were more likely to recall from an outside third-person perspective in the objective circumstances condition, which implied a removed standpoint on the past. In contrast, first-person recall was more common in the experience focus condition, which implied an involved standpoint on the past.

If present influences affect which visual perspective is used to represent an event's actual occurrence, present influences might also affect source-monitoring criteria accordingly. For example, consider trying to determine whether a first-person image of a given event corresponds to real experience with that event or only to imagination. This first-person image might seem more like a memory of a real event under circumstances in which the first-person perspective is more, rather than less, likely to be used to represent the real occurrence of events. Similarly, a thirdperson image might seem more real under circumstances in which the third-person perspective is more likely used to represent an event's occurrence. This line of reasoning leads to a hypothesis regarding susceptibility to imagination inflation: People should be most susceptible when circumstances during the posttest encourage them to visualize real events from the same perspective as the one they had previously used to imagine counterfactual events. The present experiments were designed to test this hypothesis. In previous research, the role of imagery perspective in source monitoring has not been directly investigated. By focusing on imagery perspective, the present experiments extend knowledge about source-monitoring processes, as well as about imagination inflation.

Nigro and Neisser's (1983, Study 4) experiment showed that explicit instructions to frame the memory of a real past event either as an experience or as objective knowledge influenced the visual perspective the participants used to recall that event. In the context of a memory test, the wording used to elicit the participants' beliefs about what actually occurred could implicitly suggest how people should frame the events in question. In Garry et al.'s (1996) original imagination inflation experiment, as well as in subsequent investigations (e.g., Heaps \& Nash, 1999; Paddock et al., 1998), the format of the memory test seems to suggest a removed, objective framing of events:
Participants were asked how certain they were that events in question had "happened to" them. Contrast this test format with a more active one in which participants are asked how certain they are that they "remember doing" each event; this format seems to suggest framing events as experiences. If these intuitions are correct, Nigro and Neisser's results imply that people should be more likely to visualize the real occurrence of events from the first-person perspective when questioned with the remember-doing format than with the happened-to-you format. The frequency of third-person imagery should follow the opposite pattern, being greater under the happened-to-youformat than under the remember-doing format. Experiment 1 tested these predictions.

Experiment 2 investigated the implications of such an effect for source confusion in the imagination inflation procedure. Participants were directed to use a particular perspective - first person or third person-to visually imagine counterfactual childhood events. Then the participants' beliefs about the actuality of these events were measured using either the remember-doing? or the happenedto-you? test format. Responses were compared with pretest ratings to determine the effect of imagination on memory. Neither imagination perspective was expected to be inherently more convincing of real past experience than the other. Rather, it was predicted that the effect of imagination perspective on imagination inflation would depend on how the participants' memories were tested: Imagination inflation should be most likely when memory test wording encouraged the participants to visualize real events from the same perspective as they had used to imagine counterfactual ones.

\section{EXPERIMENT 1}

In Experiment 1, the participants were asked to indicate which of 28 events actually occurred in their childhood and then, for each of those, to indicate which perspective they used to recall it. All the participants were questioned about the same 28 events. However, some of the participants were questioned in a manner that implicitly suggested that those events should be framed as experiences (i.e., mark the events that you "remember doing"), whereas other participants were questioned in a manner that implicitly suggested that the events should be framed as objective knowledge (i.e., mark the events that "happened to you"). On the basis of Nigro and Neisser's (1983, Study 4) findings, it was predicted that the frequency with which the participants used each memory perspective would depend on the wording of the memory test. Specifically, the participants should be more likely to use the first-person perspective to recall real events when questioned with the active remember-doing format than when questioned with the passive happenedto-you format. On the other hand, third-person memories should be more common when the participants were questioned with the happened-to-you format than when they were questioned with the remember- doing format. 


\section{Method}

Participants. The participants were 40 Cornell University undergraduates (16 males, 23 females, 1 unidentified) enrolled in psychology or human development classes, who received extra credit for their participation. They ranged in age from 18 to 24 years, with a mean age of 20.2 years $(S D=1.23)$.

Materials and Procedure. The participants filled out a questionnaire that appeared among several other unrelated ones during an extra-credit questionnaire session. There were two versions of this questionnaire; each version was filled out by 20 randomly chosen participants. Both versions listed the same 28 childhood events (see the Appendix) and required the participants to begin by indicating which had actually occurred in their childhoods. The only differences between the two conditions were the way in which the task was framed and the verb tense used to describe the events.

In the condition meant to encourage the participants to frame events actively, as experiences, instructions directed the participants to indicate which events they "remember doing":

Below are some things that you may or may not REMEMBER DOING BEFORE YOU WERE 10 YEARS OLD. Please read each description and consider whether or not you remember doing that before you were 10 years old.

In the condition meant to encourage the participants to frame events passively, as objective knowledge, instructions directed the participants to indicate which events had "happened to" them:

Below are some things that may or may not have HAPPENED TO YOU BEFORE YOU WERE 10 YEARS OLD. Please read each description and consider whether or not that happened to you before you were 10 years old.

In the remember-doing version, the events were described using the present participle form of the verb (e.g., "getting sick while at school"); in the happened-to-you version, the same events were described using the past tense (e.g., "got sick while at school"). The participants indicated their answer for each event by circling either yes or no.

Next, the questionnaire explained the distinction between firstperson and third-person memories in the following words:

In a first-person memory you see the event from the same visual perspective that you originally did; in other words, in your memory you are looking out at your surroundings through your own eyes. In a thirdperson memory you see the event from an observer's perspective; in other words, in your memory you can actually see yourself, as well as your surroundings.

Instructions directed the participants to go back to the events for which they had circled yes and indicate whether they primarily recalled that event from the first-person or the third-person perspective. If they had no visual memory of the event, they were to indicate this with an $x$.

\section{Results and Discussion}

This experiment was meant to assess the effect of questionnaire format on the visual perspective that participants used to represent the real occurrence of events. Thus, analyses were conducted using only the events that the participants had endorsed with a yes response to indicate that they had actually occurred. The participants in the remember-doing condition endorsed fewer of the 28 events as having occurred in their childhoods $(M=15.0$, $S D=3.40)$ than did the participants in the happened-toyou condition $[M=17.0, S D=2.81 ; t(38)=2.00, p=$ $.05]$. To account for this variation, overall number of endorsed events was used as the covariate in all the analyses. The number of endorsed events for which the participants reported having no visual memory was small in both conditions (remember-doing, $M=1.70, S D=0.90$; happened-

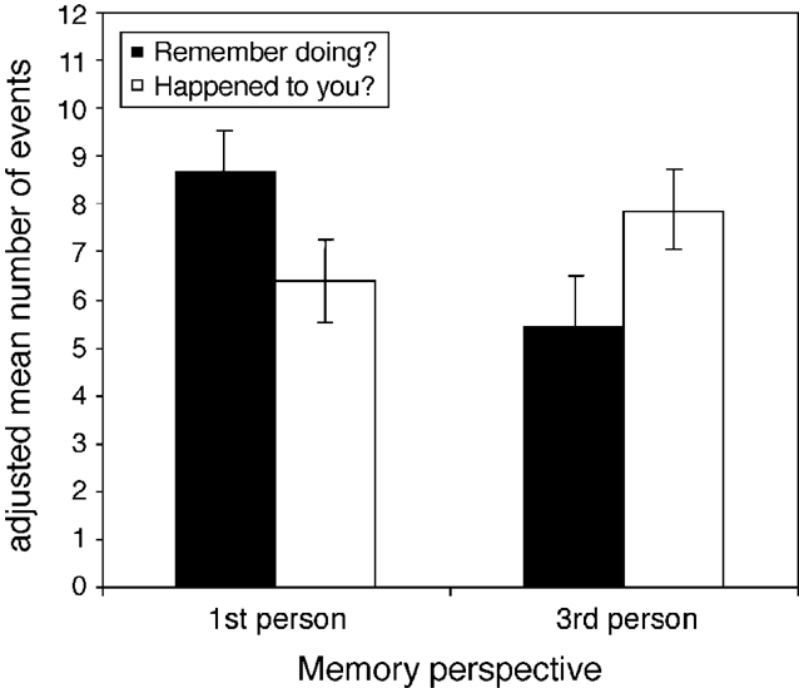

Figure 1. Mean number of events $( \pm S E)$ recalled from each perspective in the two conditions of Experiment 1, adjusted for total number of endorsed events.

to-you, $M=1.85, S D=0.73$ ) and did not differ significantly between conditions $[F(1,37)<1]$.

As was predicted, the frequency with which the participants used each memory perspective did depend on the wording of the memory test they received. Figure 1 shows the mean number of endorsed events that the participants recalled from each visual perspective, adjusted for total number of endorsed events. The number of events recalled from each perspective was submitted to a 2 (test format: remember doing vs. happened to you) $\times 2$ (memory perspective: first person vs. third person) analysis of covariance (ANCOVA) with repeated measures on the second factor. This analysis revealed an interaction between test format and memory perspective $\left[F(1,37)=4.03, M S_{\mathrm{e}}=24.43\right.$, $p=.05]$. No other effects were significant $\left[F_{\mathrm{s}}(1,37)<1\right]$. Two further ANCOVAs suggested that the nature of this interaction was as predicted. First-person memories were more common when the participants were questioned with the remember-doing format than when questioned with the happened-to-you format $\left[F(1,37)=3.92, M S_{\mathrm{e}}=12.02\right.$, $p<.05$, one-tailed]. Third-person memories were more common when the participants were questioned with the happened-to-you format than when questioned with the remember-doing format $\left[F(1,37)=3.50, M S_{\mathrm{e}}=14.68\right.$, $p<.05$, one-tailed].

The participants in Experiment 1 were asked to evaluate a wide range of childhood events; therefore, an additional analysis was conducted with event as the unit of analysis, to determine whether the effect of memory test format held up reliably across these different events. In the remember-doing condition, no participant indicated that he or she had seen lightning strike a tree; in the happenedto-you condition, no participant indicated that he or she had broken a window with his or her hand. Because these events have incomplete data for the event-level analyses, 
they were not included. Across events, the mean proportion of participants who reported no visual memory was low in both conditions (remember doing, $M=.11, S D=$ .11 ; happened to you, $M=.14, S D=.13$ ) and did not differ significantly $[t(25)=0.59, p=.56]$.

Table 1 displays the mean proportion of participants per event in each condition who recalled from each perspective. Consistent with the results from the participant-level analysis, the frequency with which events were recalled from each memory perspective depended on the format of the questionnaire. A 2 (memory test format: remember doing vs. happened to you) $\times 2$ (memory perspective: first person vs. third person) analysis of variance (ANOVA) with repeated measures on both factors revealed that this interaction was significant $\left[F(1,25)=8.87, M S_{\mathrm{e}}=0.043\right.$, $p<.01]$. There were no other significant effects in this analysis $[F \mathrm{~s}(1,25)<1]$. Further analysis verified that the nature of the interaction fit with predictions. For 19 out of 26 events that contributed data, the proportion of participants who used the first-person perspective was greater in the remember-doing condition than in the happened-toyou condition. A paired-samples $t$ test revealed that the mean difference in proportions was significant $[t(25)=$ $2.94, p<.01$, one-tailed]. Conversely, the proportion of participants who used the third-person perspective was greater in the happened-to-you condition than in the remember-doing condition for 20 of 26 events. The mean difference was also significant in this case $[t(25)=2.45$, $p<.05$, one-tailed].

In summary, the way that the participants were questioned about the past influenced the perspective they used to represent the real occurrence of events. First-person imagery was more common with the remember-doing format than with the happened-to-you format. Third-person imagery was more common with the happened-to-you format than with the remember-doing format. These results suggest that first-person imagery may better capture the experience of having performed actions than it captures objective knowledge that an event has happened; thirdperson imagery may better capture objective knowledge that an event has happened than it captures the experience of having performed the actions. If so, first-person imagery of a counterfactual event might seem to be better evidence of a real past event when one is asked whether one remembers doing the action than if one is asked whether the event happened to one. On the other hand, third-person imagery of a counterfactual event might seem to be more

Table 1

Experiment 1: Mean Proportion of Participants per Event Who Recalled From Each Perspective in Each Condition

\begin{tabular}{|c|c|c|c|c|}
\hline \multirow[b]{3}{*}{ Condition } & \multicolumn{4}{|c|}{ Test Format } \\
\hline & \multicolumn{2}{|c|}{ Remember Doing? } & \multicolumn{2}{|c|}{ Happened to You? } \\
\hline & $M$ & $S E$ & $M$ & $S E$ \\
\hline First person & .52 & .04 & .39 & .03 \\
\hline Third person & .36 & .03 & .47 & .04 \\
\hline
\end{tabular}

Note-In all cases, proportions were calculated out of the total number of participants in each condition who reported that the event did occur. convincing evidence of a real past event when one is asked whether the event happened to one than if asked whether one remembers doing it. Experiment 2 tested these possibilities, using the imagination inflation procedure.

\section{EXPERIMENT 2}

The standard imagination inflation procedure developed by Garry et al. (1996) involves three parts: (1) a pretest Life Events Inventory (LEI), on which participants indicate their degree of certainty that a number of events actually occurred in their childhood, (2) an imagination session that occurs approximately 2 weeks later, in which the participants imagine a subset of counterfactual events from the LEI as having occurred in their childhood, and (3) a posttest LEI that occurs at the end of the imagination session, in which the participants rerate their certainty about all of the events on the LEI. The effect of imagination on inflation of certainty can be assessed by comparing the number of imagined counterfactual events on which certainty increased with the number of nonimagined counterfactual events on which certainty increased.

The present Experiment 2 followed the same three steps as those in Garry et al.'s (1996) procedure but added two manipulations: the imagery perspective the participants used to imagine target events and the format of the question used to test the participants' memory regarding the actual occurrence of those events. Thus, Experiment 2 involved a 2 (imagination perspective: first person vs. third person) $\times 2$ (test format: remember doing vs. happened to you) fully between-subjects design. Imagination inflation was expected to be most likely when there was a match between memory test wording and the visual perspective used to imagine counterfactual events. Specifically, imagination inflation should be greater when the test format encourages use of the imagination perspective for representing the real occurrence of events (first-person imagination/ remember-doing?, third-person imagination/happened-toyou?) as opposed to when the test format discourages use of the imagination perspective for representing real events (first-person imagination/happened-to-you?,third-person imagination/remember-doing?).

\section{Method}

Participants. The participants were 158 Cornell University undergraduates enrolled in psychology or human development classes, who received extra credit for their participation. Two participants were excluded from analyses because they rated all of the nonimagined target events higher than the certainty midpoint on the pretest. This left 156 participants (63 males and 93 females), who ranged in age from 17 to 24 years, with a mean age of 18.8 years $(S D=1.12)$.

\section{Materials and Procedure}

Memory test formats. There were two versions of the LEI used to test the participants' memory in Experiment 2. Similar to Experiment 1 , one version asked the participants how certain they were that they "remember doing" each of the events; the other version asked the participants how certain they were that each event "happened to them." The instructions in the remember-doing condition were as follows: 
yOu REMEMBER DOING each of the following (or something very similar) BEFORE YOU WERE 10 YEARS OLD.

In the happened-to-you condition, the instructions were those originally used by Garry et al. (1996):

Below are some things that may or may not have HAPPENED TO YOU BEFORE YOU WERE 10 YEARS OLD. Please indicate how certain you are that each of the following (or something very similar) HAPPENED TO YOU BEFORE YOU WERE 10 YEARS OLD.

Both versions of the LEI listed the same 20 events. As in Experiment 1 , the only differences between the two versions of the LEI were the way in which the memory task was framed and the verb tense used to describe the events. For each event, the participants rated their certainty on a scale ranging from 1 (definitely did not happen to you or definitely do not remember doing, depending on condition) to 8 (definitely did happen to you or definitely do remember doing, depending on condition). The participants were randomly assigned to test format and filled out the same version at pretest and posttest.

Imagination session. Approximately 2 weeks after the pretest administration of the LEI, the participants took part in the imagination session in groups of 1 to 5. There were two sets of three target events (Set A and Set B) that appeared on the LEI; all but one had been used in previous imagination inflation experiments (Garry et al., 1996; Heaps \& Nash, 1999; Paddock et al., 1998). Table 2 lists the target events in each set, as well as the proportion of participants in each condition who initially reported that each event likely had not occurred in their childhood (i.e., gave ratings of 1-4, which is below the midpoint of the pretest certainty scale, which ranged from 1 to 8). As a group, all the participants in a session were randomly assigned to imagine one of the two sets of target events from either the first-person or the third-person perspective, with the stipulation that there be an approximately equal number of participants in each condition. Within the same imagination session, there could be participants from both test format conditions. The experimenter remained unaware of the participants' test format conditions throughout the imagination session.

The participants were told that the purpose of the experiment was to investigate how vividly and completely people can imagine events in different ways and that they would be given particular instructions for imagining certain events occurring about 10 years ago in their own lives. The participants received booklets containing the materials for the imagination task; the front page had instructions directing the participants to use the first-person or the third-person visual perspective (depending on condition) when imagining events. Specifically, these instructions were as follows (first-person instructions in brackets):

You should picture each event from a [first-person] third-person visual perspective. This means that you see the event in your mind [from the same visual perspective that you would have had if you were experiencing the event; in other words, you see the event through your own eyes, looking out at the situation around you.] from the visual perspective an outside observer would have had if the event were happening to you; in other words, you can see yourself in the image, as well as other aspects of the situation.

After the participants had read these and the rest of the instructions for the procedure, the experimenter directed the participants to close their eyes and form an image of the first event as he described it slowly (e.g., "Imagine that you're riding in a car on the way to the store. [10-sec pause] The car pulls into the parking lot and parks in a space. You're just about to get out of the car to go into the store"). After the experimenter had described the setting, the participants held their image in their minds while they opened their eyes and, on spaces provided in their booklets, wrote answers to three questions that the experimenter read aloud (e.g., "Where in the car were you sitting?"). After answering the questions, the participants closed their eyes again and continued imagining the event as the experimenter described it (e.g., "You get out of the car and as you're walking towards the store you see a piece of paper on the ground near the door. As you get close you see that it is a $\$ 10$ bill"). The experimenter paused for $10 \mathrm{sec}$ after finishing the scripted scenario and then, depending on condition, directed the participants to use either the first-person or the third-person visual perspective to imagine what happened next. When the participants got that image in their minds, they held it there while they wrote a detailed description of it in a space on the response sheet.

Table 2

Experiment 2: Proportion of Participants in Each Condition Who Rated Target Events Below the LEI Pretest Certainty Midpoint

\begin{tabular}{|c|c|c|c|c|c|c|c|c|}
\hline \multirow[b]{4}{*}{ Events } & \multicolumn{8}{|c|}{ Test Format } \\
\hline & \multicolumn{4}{|c|}{ Remember Doing? } & \multicolumn{4}{|c|}{ Happened to You? } \\
\hline & \multicolumn{2}{|c|}{$\begin{array}{l}\text { First-Person } \\
\text { Imagination }\end{array}$} & \multicolumn{2}{|c|}{$\begin{array}{l}\text { Third-Person } \\
\text { Imagination }\end{array}$} & \multicolumn{2}{|c|}{$\begin{array}{l}\text { First-Person } \\
\text { Imagination }\end{array}$} & \multicolumn{2}{|c|}{$\begin{array}{l}\text { Third-Person } \\
\text { Imagination }\end{array}$} \\
\hline & IM & $\mathrm{NI}$ & IM & $\mathrm{NI}$ & IM & NI & IM & NI \\
\hline \multicolumn{9}{|l|}{ Set A } \\
\hline $\begin{array}{l}\text { Broke [breaking] a window } \\
\text { with your [my] hand* }+\dagger\end{array}$ & 1.00 & 1.00 & .90 & 1.00 & 1.00 & 1.00 & 1.00 & .95 \\
\hline $\begin{array}{l}\text { Got [Getting] stuck in a tree } \\
\text { and having to have someone } \\
\text { help you [me] down* } * \dagger\end{array}$ & 1.00 & .90 & .65 & .85 & .90 & .68 & .88 & .74 \\
\hline $\begin{array}{l}\text { Found [Finding] a } \$ 10 \text { bill } \\
\text { in a parking lot } * \dagger\end{array}$ & .91 & .75 & .85 & .80 & .95 & .58 & .88 & .42 \\
\hline \multicolumn{9}{|l|}{ Set B } \\
\hline $\begin{array}{l}\text { Had [Having] a lifeguard pull } \\
\text { you [me] out of the water* }\end{array}$ & .86 & .80 & .90 & .95 & .95 & .90 & .94 & .95 \\
\hline $\begin{array}{l}\text { Got [Getting] in trouble } \\
\text { for calling } 911^{*}\end{array}$ & .91 & 1.00 & .95 & .95 & .95 & .90 & 1.00 & 1.00 \\
\hline $\begin{array}{l}\text { Saw [Seeing] lightning } \\
\text { strike a tree }\end{array}$ & .95 & .90 & .95 & .90 & .85 & .95 & 1.00 & .95 \\
\hline
\end{tabular}

Note-Proportions are out of 17-21 participants per cell. Words in brackets were substituted in the remember-doing format. LEI, life events inventory; IM, imagined; NI, not imagined. *Events used by Garry, Manning, Loftus, and Sherman (1996). †Events used by Paddock et al. (1998). †Event used by Heaps and Nash (1999). 
After $2.5 \mathrm{~min}$, the experimenter directed the participants to stop writing. On the next page, they then rated (1) the difficulty of imagining the event from the specified perspective, using a scale ranging from 1 (extremely easy) to 7 (extremely difficult), (2) the vividness of the images that they pictured, using a scale ranging from 1 (foggy and blurry) to 7 (clear and distinct), and (3) the completeness of the images, using a scale ranging from 1 (sparse and empty) to 7 (rich and detailed). Then the procedure was repeated for the next event.

The participants imagined four events in total. The first event, almost getting hit by a car, was the same for all the participants. It did not appear on the LEI and, unbeknownst to the participants, served as a practice event. The remaining three events in the session were either the events in Set A or those in Set B, depending on counterbalancing. It is important to note that the event scripts and image quality questions did not differ across the two perspective conditions; the only difference between the two conditions was the perspective the participants were directed to use when imagining the events.

When the participants had finished imagining and answering questions about all four events, they completed a 5-min filler questionnaire about imagination (e.g., "How often do you visually imagine events happening in the past?"). The purpose of this questionnaire was to insert a delay between the imagination procedure and the posttest LEI.

When all the participants had completed the filler questionnaire, they went on to the posttest LEI-either the remember-doing format or the happened-to-you format. The experimenter pointed out that this questionnaire was the same as the one the participants had filled out when they had signed up for the study and said, "We'd like you to fill out this questionnaire again. Please try to remember, as best you can, how you filled this out before." Materials had been prepared for each participant ahead of time to ensure that each participant received the same format of the LEI during posttest as they had at pretest. At the end of the session, the participants were fully debriefed and thanked for taking part.

\section{Results and Discussion}

The focus of this experiment, as for other imagination inflation experiments, was on how imagining counterfactual (as opposed to actual) events affects memory. Therefore, as in previous imagination inflation experiments, all the analyses were confined to the events that the participants' pretest ratings suggested were unlikely to have actually occurred (i.e., the event was rated below the midpoint of the pretest certainty scale). The prediction was that imagination inflation would depend on the match between imagination perspective and test format: Imagining counterfactual events would be more likely to increase certainty beyond baseline no-imagine levels when the test format had encouraged the participants to represent the real occurrence of events from the same perspective as the one they had used to imagine counterfactual events (first-person imagination/remember-doing?, third-person imagination/ happened-to-you?), as opposed to when the test format had discouraged the participants from using the imagination perspective to represent the real occurrence of events (first-person imagination/happened-to-you?,third-person imagination/remember-doing?).

Table 3 displays the mean number of imagined and nonimagined counterfactual target events for which the participants in the four conditions inflated certainty from pretest to posttest. To test the prediction, an imagination inflation score was first computed for each participant by subtracting the number of nonimagined events that showed increased certainty from the number of imagined events that showed increased certainty. Then these scores were submitted to a 2 (imagination perspective: first person vs. third person) $\times 2$ (test format: remember doing vs. happened to you) ANCOVA. Total numbers of counterfactual imagined and nonimagined target events were the covariates, included to account for the fact that some of the participants rated some target events above the certainty midpoint on the pretest. Figure 2 displays the imagination inflation scores, adjusted for differences in the covariates. Consistent with the prediction, there was a significant interaction between imagination perspective and test format $\left[F(1,150)=7.59, M S_{\mathrm{e}}=0.71, p<.01\right]$. The only other significant effect was that for one of the covariates, the total number of nonimagined counterfactual target events $[F(1,150)=8.58, p<.01]$.

Two further ANCOVAs verified that the nature of this interaction was consistent with the prediction that imagination inflation would be greatest when memory test wording had encouraged the participants to visualize real events from the same perspective as the one used to imagine the counterfactual ones. In Experiment 1, the participants were more likely to use the first-person perspective to visualize real past events when questioned with the rememberdoing format than when questioned with the happened-toyou format. In Experiment 2, first-person imagining appeared to have produced greater source confusion-and thereby, greater imagination inflation - when the participants were questioned with the remember-doing format than when questioned with the happened-to-you format $\left[F(1,76)=3.31, M S_{\mathrm{e}}=0.84, p<.05\right.$, one-tailed $]$. In Experiment 1, the participants were more likely to use the third-person perspective to visualize real past events when questioned with the happened-to-you format than when questioned with the remember-doing format. Similarly, in

Table 3

Experiment 2: Mean Number of Imagined and Nonimagined Events on Which Participants Showed Certainty Inflation in Each Condition

\begin{tabular}{|c|c|c|c|c|c|c|c|c|}
\hline \multirow[b]{4}{*}{ Target Events } & \multicolumn{8}{|c|}{ Test Format } \\
\hline & \multicolumn{4}{|c|}{ Remember Doing } & \multicolumn{4}{|c|}{ Happened to You } \\
\hline & \multicolumn{2}{|c|}{$\begin{array}{l}\text { First-Person } \\
\text { Imagination } \\
\end{array}$} & \multicolumn{2}{|c|}{$\begin{array}{l}\text { Third-Person } \\
\text { Imagination } \\
\end{array}$} & \multicolumn{2}{|c|}{$\begin{array}{l}\text { First-person } \\
\text { Imagination }\end{array}$} & \multicolumn{2}{|c|}{$\begin{array}{l}\text { Third-person } \\
\text { Imagination }\end{array}$} \\
\hline & $M$ & $S E$ & $M$ & $S E$ & $M$ & $S E$ & $M$ & $S E$ \\
\hline Imagined & .85 & .13 & .58 & .13 & .54 & .13 & .69 & .14 \\
\hline Non-imagined & .61 & .12 & .73 & .12 & .62 & .12 & .36 & .13 \\
\hline
\end{tabular}




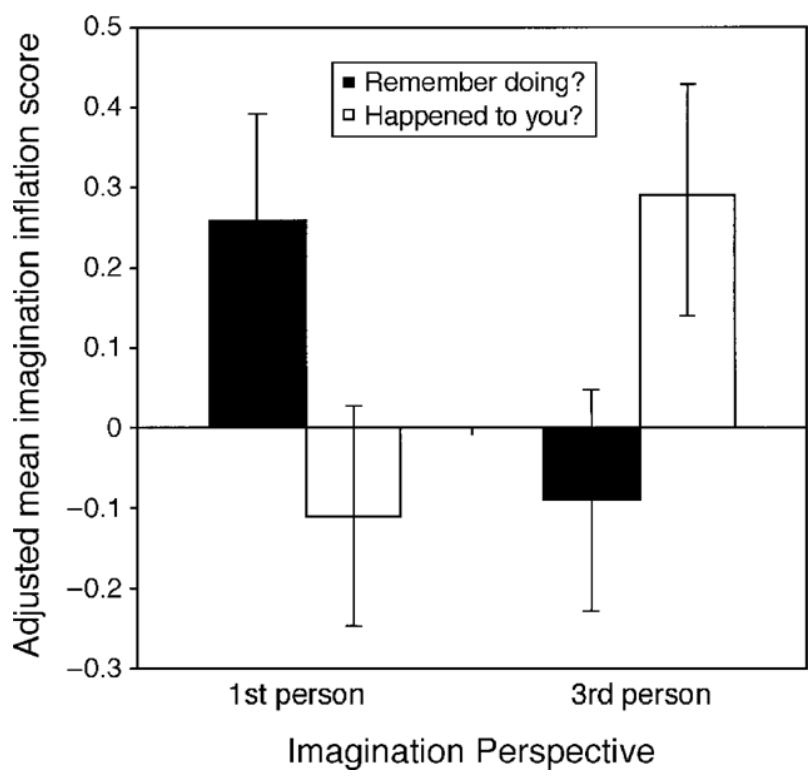

Figure 2. Mean imagination inflation score $( \pm S E)$ in the four conditions of Experiment 2, adjusted for total number of imagined and nonimagined counterfactual target events. Imagination inflation scores were calculated for each participant by subtracting the total number of nonimagined counterfactual target events for which certainty increased from the total number of imagined counterfactual target events for which certainty increased.

Experiment 2, third-person imagining produced greater inflation when the participants were tested with the happened-to-you format than when they were tested with the remember-doing format $\left[F(1,72)=4.62, M S_{\mathrm{e}}=0.59\right.$, $p<.05$, one-tailed].

This account of the imagination perspective $\times$ test format interaction assumes that the effect is not produced until the posttest, when test format determines the sourcemonitoring criteria that the participants adopt regarding the perspective of event imagery. An alternative account is that the match between pretest format and imagination perspective affected the quality of the images that the participants created during the imagination session. By this account, the imagination inflation results were a product of the imaginary representation alone (as opposed to the fit between representation characteristics and decision criteria): The participants in the imagination-perspective/ test-format match conditions created better images during the imagination phase, and for this reason, these images were more compelling at posttest. Because the participants filled out the pretest LEI approximately 2 weeks before taking part in the imagination session, it seems unlikely that pretest format would have had an effect during the imagination phase. However, if such an effect were contributing to the pattern of imagination inflation results, the participants' ratings of image quality during the imagination session could be expected to show evidence for it.

For each counterfactual imagined event, ratings of vividness and completeness and reverse-scored ratings of difficulty were standardized and summed (Cronbach's $\alpha \mathrm{s}=.81, .82$, and .82 for the first, second, and third events, respectively). These sums were averaged across all imagined events and submitted to a 2 (imagination perspective: first person vs. third person) $\times 2$ (test format: remember doing vs. happened to you) ANOVA. The interaction was not significant $[F(1,152)<1]$. There was a marginal main effect of imagination perspective: The participants told to imagine from the third-person perspective had marginally higher image quality scores $(M=0.33$, $S D=1.87$ ) than did the participants told to imagine from the first-person perspective $[M=-0.27, S D=2.11$; $\left.F(1,152)=3.34, M S_{\mathrm{e}}=4.01, p=.07\right]$. However, this main effect alone cannot explain the interaction between imagination perspective and test format on imagination inflation. Indeed, when image quality score was included as an additional covariate in the $2 \times 2$ ANCOVA that had previously revealed the significant interaction effect on imagination inflation, image quality was not a significant predictor of imagination inflation $[F(1,149)<1]$, and the imagination perspective $X$ test format interaction was virtually unchanged $\left[F(1,149)=7.53, M S_{\mathrm{e}}=0.72, p<.01\right]$.

Finally, to determine whether the interaction between imagination perspective and test format held up across the different events used in this experiment, the data were analyzed using event as the unit of analysis. Table 4 displays the proportion of participants under each of the four conditions of Experiment 2 who increased certainty after imagining and not imagining each event; in each condition, the difference between these two proportions represents imagination inflation. The pattern of these differences suggests that, as was true at the participant level of analysis, inflation of certainty beyond baseline no-imagination levels was greater when test format matched, rather than mismatched, the perspective used to imagine events. Inflation scores were submitted to a 2 (imagination perspective: first person vs. third person) $\times 2$ (test format: remember doing vs. happened to you) fully within-subjects ANOVA. Indeed, the interaction was significant $[F(1,5)=$ $\left.6.46, M S_{\mathrm{e}}=0.015, p=.05\right]$. There were no other significant effects $\left[F_{\mathrm{S}}(1,5)<1\right]$.

Overall, the data from Experiment 2 show that imagination inflation was most likely when memory test wording encouraged the participants to visualize real events from the same perspective as the one they had used to imagine counterfactual ones. These results could not be explained by the participants' ratings of general image quality. Thus, the data are consistent with the idea that the participants were using imagery perspective when making sourcemonitoring decisions on the posttest and that greater source confusion was experienced when test format encouraged the imagination perspective for representing the real occurrence of events.

\section{GENERAL DISCUSSION}

In the opening quote of this article, James (1890/1950) proposed that what defines a representation as a memory, as opposed to an imagination, is not an aspect of the rep- 
Table 4

Experiment 2: Proportion of Participants Who Increased Certainty for Each Target Event Under Each Condition

Test Format

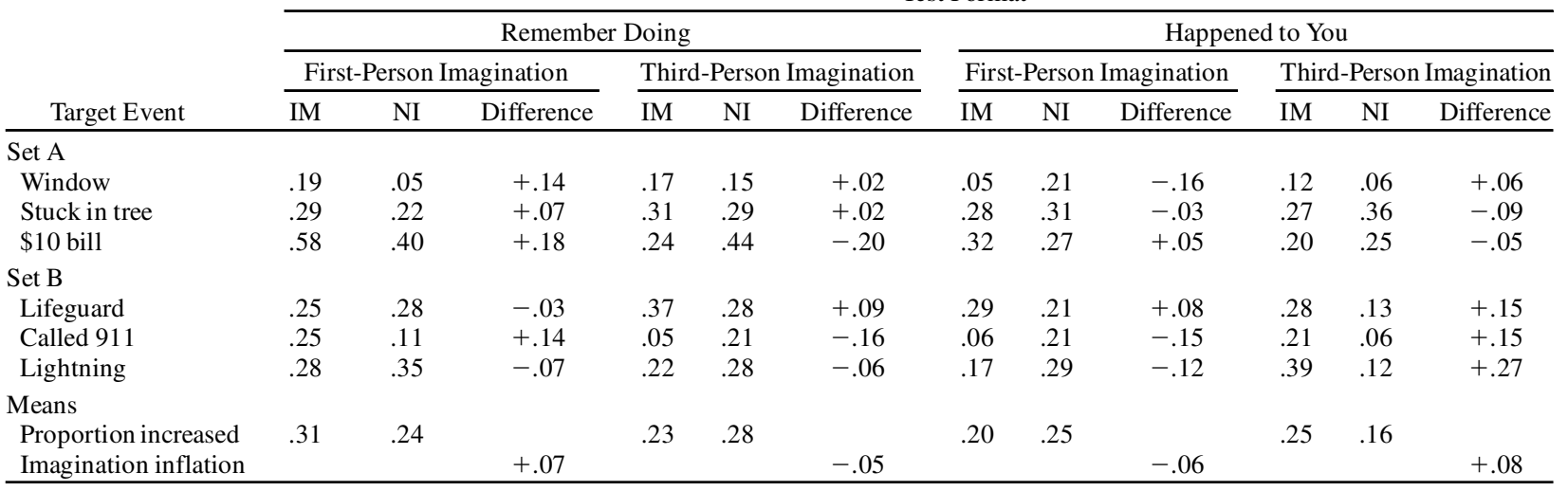

Note-Proportions are out of the total number of participants in each condition who rated the target events below the midpoint of the pretest certainty scale. IM, imagined; NI, not imagined.

resentation itself but, rather, is "the emotion of belief" that adheres to that representation. The present results are consistent with this idea and demonstrate that the "emotion of belief" can change depending on present circumstances. In Experiment 1, the visual perspective that the participants used to recall real childhood events depended on how they were questioned about those events. Experiment 2 manipulated which visual perspective the participants used to imagine counterfactual events and varied the test format used to measure the effect of imagination on the participants' beliefs about the actual occurrence of those events. Neither imagination perspective was inherently more believable than the other. Rather, the participants' certainty about the reality of the imagined childhood events depended on the match between imagination perspective and test format. Certainty about imagined counterfactual events was most likely to increase when memory test wording encouraged the participants to visualize real events from the same perspective as the one they had used to imagine the counterfactual ones. These results have implications for the source-monitoring framework in general and for imagination inflation in particular.

The results of the present experiments contribute to research on the source-monitoring framework in two ways. First, the role of imagery perspective in source-monitoring decisions has not been directly studied in previous research. The present experiments show that the visual perspective of imagery can influence source-monitoring judgments. Second, the present experiments extend knowledge about the degree of flexibility in source-monitoring criteria. Previous research has shown that test format can cause people to focus on certain qualitative dimensions of memories at the expense of others when making sourcemonitoring decisions (Binks, Marsh, \& Hicks, 1999; Dodson \& Johnson, 1993; Marsh \& Hicks, 1998). The present experiments suggest the possibility of even more extreme changes in source-monitoring criteria in response to present influences. There was no main effect of imagination perspective on imagination inflation in Experiment 2. Rather, inflation was more likely when the test format favored, as opposed to discouraged, the imagination perspective for representing real events. The fact that the direction of the imagination perspective effect depended on test format suggests that present influences not only can cause people to attend selectively to certain qualitative dimensions when making source-monitoring decisions, but also can cause them to redefine the criteria for evaluating a single dimension-in this case, imagery perspective.

As well as speaking to the nature of source-monitoring processes, the present experiments also shed light on the mechanisms that produce imagination inflation. Garry and Polaschek (2000) proposed two kinds of source errors that could cause imagination to inflate certainty. By one account, event details (e.g., images) created during the imagination phase come to mind at test, and participants mistake the source of these to be the event's real occurrence. By the other account, it is merely the feeling of familiarity created by imagination, not the content of the event representation, that is mistaken for real past experience with the event. Previous research suggests that misattributions of familiarity, alone, can produce imagination inflation (Bernstein, Whittlesea, \& Loftus, 2002; Manning, Garry, Assefi, \& Loftus, 1999). For example, in Manning et al.'s experiment, participants either imagined themselves or other people (e.g., Bill Clinton) as having experienced the target events during the imagination phase. There was no difference in the degree of imagination inflation across the two conditions. However, the present experiments suggest that mistaking the source of imagined event representations can also contribute to imagination inflation.

Within each imagination perspective condition of Experiment 2 , the participants in both test format conditions had the same experience in the imagination session up until the posttest was administered. In fact, the participants from both test format conditions were mixed to- 
gether in the same imagination sessions. Therefore, on average, within each imagination perspective condition, the participants became equally familiar with the target events across test format conditions. This suggests that differences in imagination inflation depending on test format condition were a result of different judgments that the participants made regarding the reliability of imagined images at the time of the posttest. If the effect were due to differences in the degree of familiarity afforded by imagining from the first-person versus the third-person perspective, there should have been at least a main effect of imagination perspective on imagination inflation. There was not. Instead, there was an interaction. Therefore, it appears that the imagination inflation effect was produced by judgments made at recall that depended on the match between imagination perspective and test format. These results do not conflict with the idea that errors in monitoring the source of familiarity can contribute to imagination inflation; rather, they suggest that errors in monitoring the source of imagined event representations can be a route to imagination inflation as well.

The account of the results in this article assumes that, regardless of condition, images created during the imagination phase came to mind when the participants encountered the relevant target events on the posttest; thus, the differences between conditions were due to differences in monitoring the source of those images. This assumption seems fair: Because the participants had imagined target events less than $30 \mathrm{~min}$ before the posttest, the mere mention of the target events on the posttest would likely cue the images that they had created during the imagination phase, regardless of condition. However, in cases in which events have been imagined at longer intervals before making judgments about what actually occurred in the past (as might be the case in more naturalistic settings), imagery perspective and question format might influence imagination inflation via cuing effects, as well as source-monitoring errors. In these cases, simply mentioning the event during questioning may not necessarily bring the imagined representations to mind. Given encoding specificity effects (e.g., Barclay, Bransford, Franks, McCarrell, \& Nitsch, 1974; Thomson \& Tulving, 1970), it is possible that people questioned in a format that instates the same perspective on the past as the one that was used during imagination might be more likely than people questioned in an alternate format to recall the images that they imagined earlier. Then, as was argued to be the case in the present experiments, people for whom the imagination perspective matched question format would also experience more confusion when deciding the source of those images. If this account is true, the match between imagination perspective and test format might become increasingly important in determining imagination inflation as the interval between imagination and questioning increases, because both cuing and source-monitoring errors might contribute to imagination inflation at longer intervals.

In summary, the present results suggest that imagination inflation is produced not simply by the imagined rep- resentation itself, but also by the interaction between the characteristics of that representation and the sourcemonitoring criteria applied at test. This interaction is what determines how much the imagined representation seems like a representation of real past experience. Differences in the extent to which imagination contaminated memory could not be accounted for simply by differences in the visual perspective that the participants used to construct imaginary representations of the past. The participants' expectations for the visual perspective of memories for actual events mattered, and these expectations changed depending on present influences. To summarize in James's (1890/1950) terms, the experiments reported here suggest that the emotion of belief adheres more strongly to imaginary representations of the past that are viewed from the same perspective as the one used to represent the real occurrence of events, whichever perspective that may be.

\section{REFERENCES}

Barclay, J. R., Bransford, J. D., Franks, J. J., McCarrell, N. S., \& Nitsch, K. (1974). Comprehension and semantic flexibility. Journal of Verbal Learning \& Verbal Behavior, 13, 471-481.

Bernstein, D. M., Whittlesea, B. W. A., \& Loftus, E. F. (2002). Increasing confidence in remote autobiographical memory and general knowledge: Extensions of the revelation effect. Memory \& Cognition, 30, 432-438.

Binks, M. L., Marsh, R. L., \& Hicks, J. L. (1999). An alternative conceptualization to memory "strength" in reality monitoring. Journal of Experimental Psychology: Learning, Memory, \& Cognition, 25, 804-809.

Dodson, C. S., \& Johnson, M. K. (1993). Rate of false source attributions depends on how questions are asked. American Journal of Psychology, 106, 541-557.

Garry, M., Manning, C. G., Loftus, E. F., \& Sherman, S. J. (1996). Imagination inflation: Imagining a childhood event inflates confidence that it occurred. Psychonomic Bulletin \& Review, 3, 208-214.

Garry, M., \& PolascheK, D. L. L. (2000). Imagination and memory. Current Directions in Psychological Science, 9, 6-10.

Goff, L. M., \& RoEdiger, H. L., III (1998). Imagination inflation for action events: Repeated imaginings lead to illusory recollections. Memory \& Cognition, 26, 20-33.

HEAPS, C., \& NASH, M. (1999). Individual differences in imagination inflation. Psychonomic Bulletin \& Review, 6, 313-318.

JAMES, W. (1950). The principles of psychology (Vol. 1). New York: Dover. (Originally published 1890)

Johnson, M. K., Foley, M., Suengas, A. G., \& Raye, C. L. (1988). Phenomenal characteristics of memories for perceived and imagined autobiographical events. Journal of Experimental Psychology: General, 117, 371-376.

Johnson, M. K., Hashtroudi, S., \& Lindsay, D. S. (1993). Source monitoring. Psychological Bulletin, 114, 3-28.

Johnson, M. K., Nolde, S. F., Mather, M., Kounios, J., Schacter, D. L., \& CURRAN, T. (1997). The similarity of brain activity associated with true and false recognition memory depends on test format. Psychological Science, 8, 250-257.

Johnson, M. K., Raye, C. L., Foley, H. J., \& Foley, M. A. (1981). Cognitive operations and decision bias in reality monitoring. American Journal of Psychology, 94, 37-64.

Liвby, L. K. (2003). Seeing meaning: Imagery perspective, action identification, and perceptions of change in the self. Unpublished doctoral dissertation, Cornell University.

Liввy, L. K., \& EiвAсH, R. P. (2002). Looking back in time: Selfconcept change affects visual perspective in autobiographical memory. Journal of Personality \& Social Psychology, 2, 167-179.

LindSAY, D. S., \& Johnson, M. K. (1989). The eyewitness suggestibility effect and memory for source. Memory \& Cognition, 17, 349-358. Manning, C. G., Garry, M., Assefi, S., \& Loftus, E. F. (1999). Imag- 
ination inflation: Changing autobiographical memory by imagining others. Unpublished manuscript.

MARSh, R. L., \& Hicks, J. L. (1998). Test formats change sourcemonitoring decision process. Journal of Experimental Psychology: Learning, Memory, \& Cognition, 24, 1137-1151.

Nigro, G., \& Neisser, U. (1983). Point of view in personal memories. Cognitive Psychology, 15, 467-482.

Paddock, J. R, Joseph, A. L., Chan, F. M., Terranova,S., Manning, C.,
\& LofTUS, E. F. (1998). When guided visualization procedures may backfire: Imagination inflation and predicting individual differences in suggestibility. Applied Cognitive Psychology, 12, S63-S75.

Robinson, J. A., \& Swanson, K. L. (1993). Field and observer modes of remembering. Memory, 1, 169-184.

Thomson, D. M., \& Tulving, E. (1970). Associative encoding and retrieval: Weak and strong cues. Journal of Experimental Psychology, 86, 255-262.

\section{APPENDIX \\ Events Used in the Memory Test of Experiment 1}

1. Got [Getting] sick while at school

2. Went [Going] swimming in the ocean

3. Flew [Flying] in an airplane

4. Gave [Giving] a birthday gift to a family member

5. Ate [Eating] a meal at a picnic

6. Arrived [Arriving] late to school

7. Attended [Attending] a religious service or ceremony

8. Fell [Falling] into the water at a pool or lake

9. Won [Winning] a competition

10. Found [Finding] a 10 dollar bill in a parking lot

11. Went [Going] ice skating

12. Played [Playing] a board game

13. Got [Getting] sick and had [having] to go to the emergency room late at night

14. Had [Having] a lifeguard pull you [me] out of the water

15. Went [Going] skiing

16. Visited [Visiting] a museum

17. Broke [Breaking] a window with your [my] hand

18. Won [Winning] a stuffed animal at a carnival game

19. Played [Playing] a musical instrument

20. Were [Being] homesick and/or missed your [my] parents

21. Saw [Seeing] lightning strike a tree

22. Painted [Painting] a picture

23. Got your [Getting my] finger shut in a door

24. Rode [Riding] on a bicycle

25. Got [Getting] upset about going to the dentist

26. Were [Being] lost in a public place for more than an hour

27. Got [Getting] stuck in a tree and had [having] to have someone help you [me] down 28. Broke [Breaking] a plate

Note-Words in brackets were substituted in the remember-doing condition. 